\section{Opalski’s syndrome}

When ipsilateral hemiplegia is associated with symptoms of a lateral medullary syndrome, it corresponds to the submedullary syndrome of Opalski. ${ }^{1}$ Some neuropathological case reports have shown that the infarction is located lower than that found in Wallenberg's syndrome. ${ }^{2}$ Opalski's syndrome has been attributed to an occlusion of the vertebral artery. ${ }^{3}{ }^{4}$ There are limited neuroradiological studies at the literature about this syndrome. ${ }^{5}$

We report the case of a 69 year old man, without cardiovascular risk factors, who developed a sudden left headache followed by dysarthria, dysphagia, and ataxia (falling to the left). Neurological examination disclosed a severe dysphagia with a hoarse voice, and the uvula was pulled to the right side. There was left facial weakness with sensory loss at this side and the left corneal reflex was absent with an ipsilateral miosis. Left braquiocrural hemiparesis and right (crossed) braquiocrural sensory loss were seen. Walking was not possible.
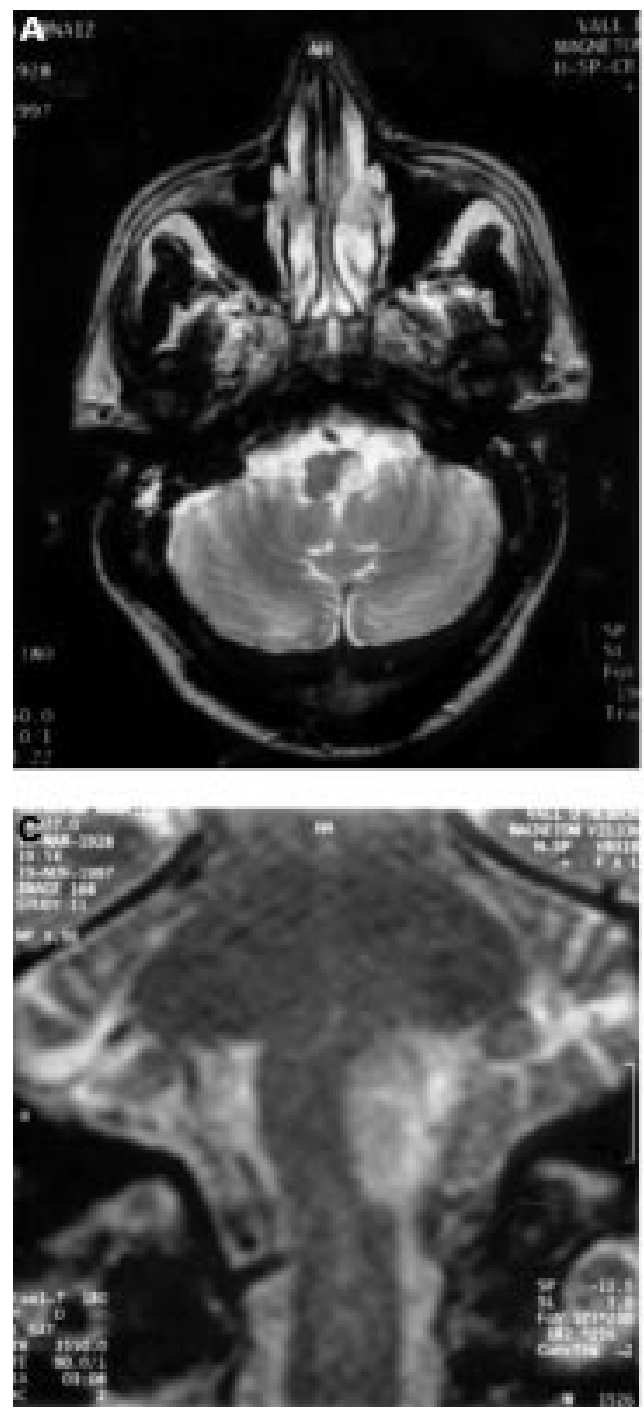

Magnetic resonance imaging (T2 weighted sequence), showed a large left laterobulbar infarction (figure A). This figure and the sagittal image (figure B) confirmed that the left pyramidal tract was unaffected. The coronal image (figure C) shows the caudal extension of the infarct, involving the right pyramidal tract after crossing to the left side. An absence of flow of the left vertebral artery is seen on MR angiography (figure D).

Ipsilateral hemiparesis was linked to the lesion of the lower medulla involving the ipsilateral corticospinal tract after decussation of the pyramids. This picture differs from the hemimedullary infarct (Babinski-Nageotte syndrome) in which the ipsilateral pyramidal tract is affected before decussation with contralateral hemiparesis.

J MONTANER J ALVAREZ-SABÍN
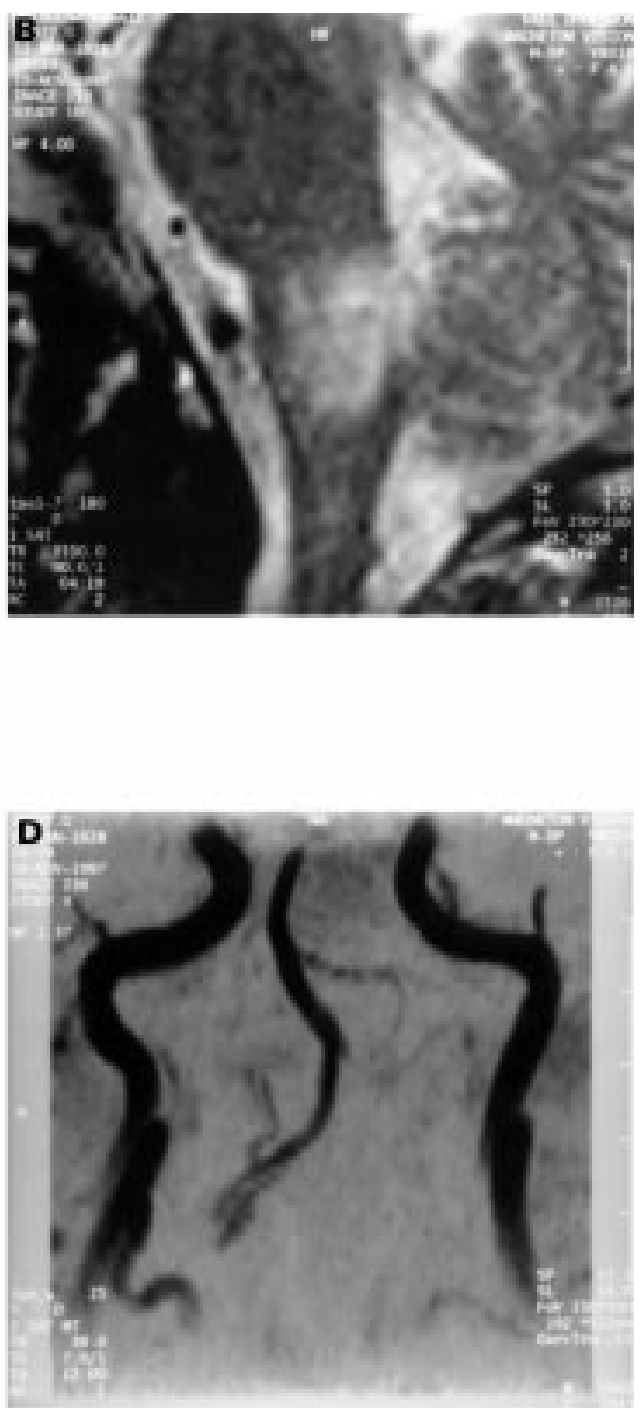
Cerebrovascular Unit, Department of Neurology, Vall d'Hebron Hospital, Barcelona, Spain

Correspondence to Dr J Montaner, Cerebrovascular Unit, Department of Neurology, Vall d'Hebron Hospital, Barcelona, Spain.

1 Opalski A. Un nouveau syndrome sous-bulbaire: syndrome partiel de l'artère vertébro-spinale postérieur. Paris Med 1946;1:214-20.
2 Osetowska E, Krasnicka Z. Sur le syndrome sous-bulbaire d'Opalski avec une étude anatomique (contribution aux aspects paradoxaux du syndrome de Wallenberg). Rev Neurol (Paris) 1961;104:314-20.

3 Dhamon SK, Iqbal J, Collins GH. Ipsilateral hemiplegia and the Wallenberg syndrome. Arch Neurol 1984;41:179-80.

4 Romero F, Molins M, Gonzalez F, et al. Síndrome de Opalski. Estudio clínico-radiológico de una observación. Rev Neurol 1975;10:11-16.

5 Hommel M, Pollak P, Gaio JM, et al. Imagerie par résonance magnétique et infarctus latérobulbaire. Rev Neurol(Paris) 1988;144:272-8. 